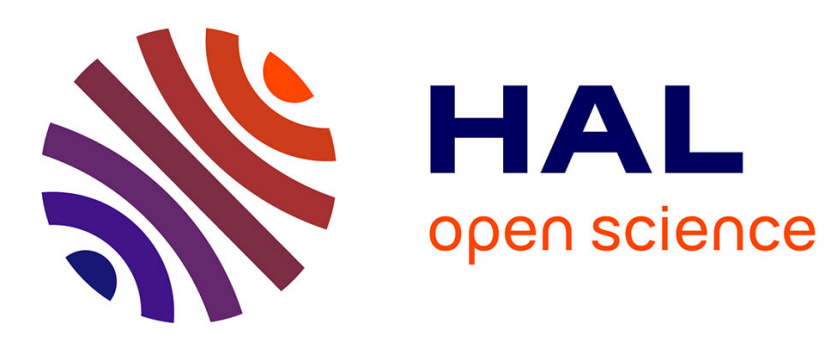

\title{
A reflection upon methods to explore timing in patients with schizophrenia
}

\author{
Brice Martin, Nicolas Franck, Anne Giersch
}

\section{To cite this version:}

Brice Martin, Nicolas Franck, Anne Giersch. A reflection upon methods to explore timing in patients with schizophrenia. PsyCh Journal, 2019, ALTERED STATES OF CONSCIOUSNESS, 8 (1), pp.8289. $10.1002 /$ pchj.268 . hal-02974573

\section{HAL Id: hal-02974573 \\ https://hal.science/hal-02974573}

Submitted on 21 Oct 2020

HAL is a multi-disciplinary open access archive for the deposit and dissemination of scientific research documents, whether they are published or not. The documents may come from teaching and research institutions in France or abroad, or from public or private research centers.
L'archive ouverte pluridisciplinaire HAL, est destinée au dépôt et à la diffusion de documents scientifiques de niveau recherche, publiés ou non, émanant des établissements d'enseignement et de recherche français ou étrangers, des laboratoires publics ou privés. 


\section{A reflection upon methods to explore timing in patients with schizophrenia}

Brice Martin 1, Nicolas Franck, 1, Anne Giersch, 2

${ }^{1}$ Resource Center for Psychosocial Rehabilitation and Cognitive Remediation, Le Vinatier Hospital UMR 5229 CNRS \& Université Lyon 1, Université de Lyon, Lyon, France

${ }^{2}$ INSERM U1114, Psychiatric Center, University of Strasbourg, Regional University Hospital of Strasbourg, University of Strasbourg, Strasbourg, France

Correspondence to: Dr. Brice Martin, Centre Ressource de Réhabilitation Psychosociale et de Remédiation Cognitive Fédération de Centre Référent Lyonnais en Réhabilitation et en Remédiation cognitive (CL3R), Hôpital du Vinatier, CNRS UMR 5229, 69008 Lyon, France. Email: brice.martin@ch-le-vinatier.fr 


\begin{abstract}
Phenomenologists have provided a detailed description of the disorders of the subjective experience associated with minimal self disorders in patients with schizophrenia. Those patients report a range of distortions of their conscious experiences, including a sense of inner void, confusion between self and others, and, sometimes, a disruption of the sense of time. These reports have been interpreted as distortion of the first-person perspective and a lack of immersion in the world, associated with a breakdown of the temporal structure of consciousness, and especially a disruption of the sense of time continuity. Further, it has been proposed that these disruptions are based on a difficulty to retain past information and to predict future information, that is, the mechanisms that help to relate events with one another and to reach a sense of time continuity. Experimental psychology results seem to converge to similar conclusions, inasmuch as some results in patients with schizophrenia suggest a deficient ability to predict sequences of events at the millisecond level. Several studies have underlined this convergence. Here we reflect on the limits of both the phenomenological and experimental psychology approaches, and of the convergence of their hypotheses. We think that this reflection is necessary to avoid premature conclusions on the mechanisms underlying the impairments in patients, but also to enrich our understanding of schizophrenia.
\end{abstract}

Keywords: schizophrenia; self disorders; time prediction; timing 
Thomas Mann (1931) wrote in The Magic Mountain: "What is time? A mystery. Deprived of its own reality, it is all-powerful. It is a condition of the phenomenal world” (p. 473). This might well apply to schizophrenia. Schizophrenia is an invalidating pathology affecting about $1 \%$ of the population, but whose pathophysiology remains to be understood. Distinct approaches in phenomenology and experimental psychology focus on the structure of consciousness, and both emphasize the role of basic timing disorders in the genesis of the patient's conscious experience. Indeed, for both approaches, time is a key component of the structure of subjectivity, and, as such, a target for the understanding of the basic disturbances of self-consciousness in patients with schizophrenia. Here we summarize the contribution and limits of each approach before discussing advantages and pitfalls encountered when building research projects on the basis of the convergence of the hypotheses in the two domains.

\section{Schizophrenia, minimal self, and timing}

Schizophrenia and minimal-self disorders Schizophrenia is a clinical entity whose contours remain unclear (Jansson \& Parnas, 2007; Nordgaard, Revsbech, Sæbye, \& Parnas, 2012). There are a number of factors that underlie the limitation of contemporary psychopathology and the difficulty to clearly define the concept of schizophrenia. For example, it has been suggested that there is an insufficient conceptualization of psychosis and of the illness onset and a general lack of a theoretical framework for psychopathology (Parnas, 2005; Parnas \& Handest, 2003).

Based on this statement, some attempts have been made, resting on the reintroduction of the subjective experience (first-person perspective) in psychopathology, to refine the clinical description of schizophrenia (Parnas, Handest, Saebye, \& Jansson, 2003; Sass \& Parnas, 2003). This approach has led to an attractive, phenomenological model of minimal-self disorders.

The minimal self represents the basic level of the self. It refers to the implicit sense of "mineness" of experience (Nelson, Parnas, \& Sass, 2014). A normal sense of self involves automatic, not-reflexive, self 
presence and immersion in the world (Parnas et al., 2005). Thus, the minimal self refers to the basic sense of existing in a first-person perspective (Sass, 2014). It is distinct from more elaborated aspects of the self, such as the reflexive self and the narrative self (Haug et al., 2012). Minimal self refers to the basic structure of subjectivity, that is, a structure that determines the form of experience (the how of experience) rather than the particular contents of experience (the what of experience; Parnas \& Henriksen, 2014).

Minimal-self disorders can be explored empirically and in a systematic way with phenomenologically oriented tools, for example, the Examination of Anomalous Self-Experience (EASE) scale (Parnas et al., 2005). Disturbances in the mineness of personal experience have been described in detail elsewhere (Parnas et al., 2003; Sass, 2014) and consist in an alteration of the sense of mineness of body, thought, or perception. Results from empirical studies using the EASE scale (Haug et al., 2012; Nelson, Thompson, \& Yung, 2012; Nordgaard, Nilsson, Saebye, \& Parnas, 2017; Raballo \& Parnas, 2012; Raballo, Saebye, \& Parnas, 2011) have now highlighted the high specificity of minimalself disorders in the schizophrenia spectrum, suggesting that minimal-self disorders are trait markers of schizophrenia spectrum disorders (schizophrenia and schizotypal disorders). They would represent trait features that characterize the typical core of schizophrenia (Sass \& Byrom, 2015).

\section{Minimal-self disorders and schizophrenia: An expression of timing disorders?}

For years, phenomenologists have proposed that difficulties in timing represent a key issue for the psychopathology of schizophrenia. Distortions of the temporal structure of consciousness may indeed relate to basic disturbances of the self. A first important point is the type of timing concerned here. In phenomenology, time is not necessarily investigated and understood as a content of consciousness. Rather, it is a key component associated with the structure of the consciousness flow. Time appears to be a basic, “ontological” component of reality (Wiggins, Schwartz, \& Naudin, 2003). Indeed, the philosopher Edmund Husserl (2012) locates time, and, more precisely, the intimate consciousness of time 
(inneres Zeitbewusstsein), at the lowest level of our understanding of the world. Husserl describes a tripartite structure of time consciousness that is defined by the integration of the past, the present, and the future. For example, when listening to a melody, we are conscious of the present note, but we still have the previous note in mind ("retention"), and we usually anticipate the note to come ("protention"; see Gallagher \& Zahavi, 2014). In a similar way to what has been described in the domain of motor control, protention would allow us to anticipate the next thought and words when speaking. As explained by Fuchs (2007), these functions operate at the most basic layer of consciousness in an implicit, tacit, and automatic way, and can integrate the sequence of single moments into an "intentional arc." This arc allows the subject to tightly connect with the world, and originates the structure of consciousness. It should be emphasized that the term intentional does not refer to a voluntary and reflexive integration of past, present, and future moments. On the contrary it is passive. According to phenomenologists, it is a basic mechanism allowing us to consciously experience the world as being continuous in time. In a very close and more contemporary way, Pöppel (2009) explained that "one essential feature of perception or action is effortless availability” (p. 1889), which rests, in part, on timing. For Pöppel, timing is a "universal integration process ... [which] is automatic and pre-semantic, i.e. it is not determined by what is processed" (p. 1893). The time structure of information processing would shape all our experiences. Importantly it would affect our sense of self (de Warren, 2009; Fuchs, 2007). Automatic temporal synthesis (or, in Husserlian terms, “passive” temporal synthesis) takes a part in the stability of the perception of the world, allowing the subject to recognize himself in the world. "As a consequence, the actions of normal people rely on the assumption of a pre-given world, a spatial, temporal, causal, and social order that their mental lives permanently construct” in an automatic way (Wiggins et al., 2003, p. 20). The continuity and sense of immediate connection to the world and to others is all the more important when it is necessary to feel oneself as a continuous being (Giersch \& Mishara, 2017a, 2017b; Martin et al., 2014; Mishara, 2010). Time continuity is usually taken for granted. It is difficult to imagine time as being discontinuous, but this is precisely what seems to happen in patients with 
schizophrenia, who describe a fragmented consciousness flow, or an absence of time (Chapman, 1966; Fuchs, 2007; Martin, Franck, Cermolacce, Coull, \& Giersch, 2018; Minkowski, 1933). Patients relate time fragmentation with disturbances of the sense of self, for example in the following:

Time splits up and doesn't run forward anymore. These arise uncountable disparate now, now, now, all crazy and without rule or order. It is the same with myself. From moment to moment, various ‘selves' arise and disappear entirely at random. There is no connection between my present ego and the one before. (B. Kimura, cited in Fuchs, 2007, p. 233)

A fragmentation of the consciousness flow in patients with schizophrenia would be associated with the patient's disrupted ability to feel themselves as one continuous being.

A consequence of this attractive hypothesis, essentially derived from phenomenology, is to question the possibility of empirically evaluating and documenting the fundamental role of time in the genesis of self-disturbances. The question is then as follows: How is it best to evaluate the time structure of consciousness and its relationship with disturbances of the sense of self?

\section{How to explore timing in schizophrenia}

\section{Verbal report}

A first way to explore time in patients with schizophrenia consists in noting the spontaneous remarks about timing of people with schizophrenia, and by encouraging them to elaborate on this topic. Indeed, some people within the schizophrenia spectrum disorder have both a spontaneous interest in this question, and, on the other hand, sufficient elaboration capacities to try to conceptualize their own relation to time. Examples can be found in Minkowski (1933), Fuchs (2007), and Martin et al. (2018). For example, the patient A.F. (Martin et al., 2018) explained: 
"I do not feel the time,” “The word 'time' has no meaning for me.” ... “[I have to] use tools, tricks, to know that time has passed ... which does not mean much to me.” "For example, I often look at my watch to know that time has elapsed..." "You see, I can use a metaphor ... Birds, they have a sense that allows them to orient themselves ... a kind of magnetism ... It is an innate thing ... If they do not have it, they cannot navigate ... Me, it's the time I do not have ... I'm like blind to time ... but I cannot explain it better ... I try to find out how to talk about it ... but I can't manage to explain ... It may be the most important thing to understand.” (Martin et al., 2018, p. 3)

The point we can make with this clinical material lies first of all in the observation that the question of time, far from being an uninteresting topic, is a central issue for some patients. They elaborate on timing to explain their own disorder. These spontaneous elaborations can be very useful to encourage the emergence of heuristic hypotheses about the nature of what their timing disorder is about. For example, A.F. describes his own relation to timing as a basic and pre-reflective phenomenon, like seeing or hearing, and not as a high level, cognitive phenomenon.

However, the collection of spontaneous verbal material on time obviously has many limitations. On the one hand, the ability to spontaneously translate into words and to elaborate on this issue seems to concern a subset of patients, making it difficult to build cohorts of patients with timing disorders. Moreover, this type of verbal report remains difficult to use scientifically because it can hardly be translated in a quantifiable way. Finally, as underlined by Shaun Gallagher, "a report on experience is not the same thing as the experience” (Nowakowski, Podgórski, Pokropski, \& Wachowski, 2011, p. 83). It is not possible to eliminate the possibility that the patient's verbal elaborations do not reflect their true experience. This is where the phenomenological approach can be useful. 


\section{Phenomenological analysis}

The objective of phenomenology is to grasp the nature of the subject's personal experience. It can be used to understand the temporal structure of the experience of patients with schizophrenia, for example by analyzing reports of minimal-self disturbance. The verbal report (and other clues, like behavioral features) is then submitted to a structured analysis, according to the phenomenological method. The principle of this approach is to bring out the essential and invariant features of the experience lived in the first perspective by the patient, based on the patient's narrative. This method goes beyond the mere verbal report inasmuch as it mobilizes both the subjectivity of the clinician and a method named phenomenological reduction (for technical details relating to this approach, including a presentation of the method of reductions, see de Warren, 2009; Mishara, 2010; Naudin, 1998) The phenomenological reduction allows the clinician to capture the essential features of schizophrenic temporality in the same way as Husserl when he attempted to characterize normal temporality. A number of studies are based on this approach (Binswanger, 1965; Blankenburg, 1969/2001; Fuchs, 2007; Tatossian, 1979). Overall, the authors using this method describe a loss or a breakdown of temporal synthesis (i.e., of the integration of past, present, and future). Related to this difficulty, intentionality would be fragmented and even inversed. In that case, instead of listening or speaking, patients would have the impression that they are spoken to by others (Fuchs, 2007).

A major interest of this approach lies in the description of timing disorders when trying to understand the experience of patients with schizophrenia. Studies are conducted within the framework of the Husserlian model, which provides a solid conceptual and phenomenological basis. Such studies have recently led to the development of tools such as the Examination of Anomalous World Experience scale (Sass et al., 2017), a phenomenologically informed scale that includes a whole section dedicated to timing disorders (but whose psychometric properties remain to be evaluated).

However, many limitations are to be emphasized regarding the application of phenomenological reduction to schizophrenia. As a matter of fact, the only access we have to the patient's ego is through the 
reflexive analysis and reduction of their own elaboration. But how can we make a reflexive analysis when the patient's consciousness is altered? It always remains an "analysis" from the outside, like in Binswanger's (1965) work, which seems purely hypothetical insofar as the alterations of temporality are not described directly but postulated by assuming a deformation of the normal temporality. To conclude, as underlined by Shaun Gallagher, "if you are conducting experiments with subjects suffering from psychopathic delusions, it may be difficult or impossible to train them in phenomenological method" (Nowakowski et al., 2011, p. 81).

Even in healthy subjects, reduction has its limits, since there is no way of ever knowing whether the attempt has been successful (Ricoeur, 1969), inasmuch as there is no method to put the phenomenological analysis to test. Phenomenology attempts to reach the personal experience, which by definition remains personal. For example, even if two subjects name the color of an object with the same word, they cannot be sure that their personal experience is the same.

Another limit is more specifically related to the phenomenology of timing, and results from the following paradox: If time really is inherent to subjectivity, how can subjectivity be used to study its own structure without denying itself? (Buser \& Debru, 2011). As Buser and Debru (2011, p. 71) point out, Husserl introduces the idea of a passive genesis of conscious temporality, which would be more fundamental than active genesis. This passive genesis leads to an object that is not totally transparent, and which reflexive consciousness cannot fully illuminate. Naudin (1998) suggests that it is impossible to reach, in the immediacy of intuition, the original impression that is at the source of every temporal object, in other words, the very source of the living.

Buser and Debru (2011) conclude: Either the search for the original elements making temporal consciousness possible is in fact speculative, without solution, and has no other reality. Either it deserves to be taken up in an entirely different framework in which it is not entirely devoid of reality, namely that provided by cognitive neuroscience, in which temporal processes play an important role and especially phenomena of protention. 


\section{Experimental psychology}

Experimental psychology provides an alternative approach to assessing subjective time that adds to the phenomenological explorations. It limits the use of the verbal report (which is, however, not totally excluded) and has procedures allowing experimentalists to explore timing processes without requiring a conscious elaboration on time from the subjects. In all, experimental psychology offers attractive tools to explore the structure of temporality and especially "implicit timing." According to Coull and Nobre (2008), "implicit timing is engaged, even without a specific instruction to time, whenever sensorimotor information is temporally structured" (p. 137). These approaches have been used in several studies exploring timing disorders in patients with schizophrenia. Our aim here is not to describe the detail of these works extensively, especially as they have been the subject of several review papers (Giersch, Lalanne, \& Isope, 2016; Giersch, Lalanne, van Assche, \& Elliott, 2013; Giersch et al., 2015) and meta-analyses (Ciullo, Spalletta, Caltagirone, Jorge, \& Piras, 2016; Thoenes \& Oberfeld, 2017). We will only briefly summarize some of the existing data, in order to question the methods, their limits, and the way to go forward.

Many studies are based on simple paradigms in which two geometric figures are shown on a computer screen, either simultaneously or asynchronously. Subjects have to decide about the simultaneity versus asynchrony of the stimuli, or their temporal order (e.g., they have to decide which geometric figure was first displayed on the screen). Those are the studies that are closest to the concept of temporal structure (as opposed to time content, e.g. duration). Importantly, several methods have been developed or used to explore temporal processes implicitly. Such studies rely on the automatic motor responses given by the subjects, even when they are unable to consciously detect asynchronies between stimuli (Lalanne, van Assche, \& Giersch, 2012; Lalanne, van Assche, Wang, \& Giersch, 2012; Poncelet \& Giersch, 2015). Other studies rely on the manipulation of the temporal properties and their impact on performance (Martin et al., 2017; Martin, Giersch, Huron, \& van Wassenhove, 2013; Posada 
\& Franck, 2002). For example, in Martin et al. (2017), subjects had to answer as soon as they detected a target after a first fixation point. The manipulation of the interval between the first fixation point and the target (from 500 to $1500 \mathrm{~ms}$ ) allowed the authors to explore the implicit time expectation associated with the task. The results suggested that temporal expectation is fragile in patients with schizophrenia, especially in those displaying minimal-self disorders. Perturbations were observed even at the millisecond scale. Lalanne, van Assche, and Giersch (2012), Lalanne, van Assche, Wang, and Giersch (2012), and Poncelet and Giersch (2015) showed that subjects automatically react to undetectable asynchronies. It has been proposed that subjects can follow information over a time scale of milliseconds by predicting sequences of information items (see Giersch et al., 2016; Giersch \& Mishara, 2017b). According to the hypotheses put forward by the authors, healthy control subjects would anticipate the last event of the sequence and attend to it, whereas patients would remain stuck on the first stimulus of a sequence of two. Impairments in patients might be related to a difficulty to predict sequences of information at the milliseconds level (Giersch et al., 2016).

A great advantage of these approaches rests on the possibility to explore timing in schizophrenia on very small time scales, while limiting the use of verbal report. Moreover, by crossing experimental studies with explorations of the minimal self (e.g., with the EASE scale), this approach can document the hypothesis of a relationship between timing and disorders of the sense of self by means of correlations. Few studies have been conducted this way until now, but, as emphasized above, Martin et al. (2017, 2018) have shown a correlation between minimal-self disorders (assessed with the EASE scale) and temporal prediction (assessed with the preparatory setting task). A first limit here is that the assessment of correlation between clinical variable and performances on psychological test has a low scientific validity, and is certainly not enough to derive a firm conclusion. 


\section{Convergence of Experimental Psychology and Phenomenology}

What is striking is that the experimental results summarized above emphasize the importance of prediction impairments, and especially time prediction impairments in patients with schizophrenia. It is very tempting to relate these experimental results with the hypotheses that have been put forward by phenomenologists (i.e., the importance of retention and protention mechanisms that help to relate past, present, and future moments). The convergence of these hypotheses has been underlined in several recent reviews (Giersch \& Mishara, 2017a, 2017b). However, we emphasize here the limits and potential pitfalls of this convergence. Convergence does not mean causal relationships, or proof. The difficulty accessing the personal experience has already been noted above, and this is all the more true for the experimental approach, which is necessarily based on a reductionist approach. As described above, timing disorders have been objectified with geometric figures, which obviously do not equate the thought flow. These limits should be kept in mind, in order to avoid premature conclusions, and to remain cautious when using these studies to devise new therapeutic methods.

These limits do by no means impede further explorations, though. On the contrary, it is with these limits in mind that research should go forward. When inspired by phenomenology, experimental psychologists may manipulate time properties of the information presented to patients with the aim of affecting and recording both their automatic responses and their subjective experience. Such approaches could be usefully completed by imaging techniques exploring the temporal properties of the brain signals (Northoff, 2017). It could be especially useful to explore the link between abnormalities in brain activations during timing tasks and during rest, inasmuch as rest may better reflect the spontaneous train of thoughts than performance recorded when detecting asynchronies between squares. Experimental findings could also be used to attempt to logically derive potential consequences on subjectivity, which could in turn be explored with phenomenology. Inasmuch as impairments are described at an unconscious level (i.e., when information is subjectively judged as being simultaneous but is in fact asynchronous), the consequences on subjectivity are indirect and should be sought. A 
manipulation of asynchronies in the normal environment, by means of experimental psychology and/or virtual reality, may help to investigate the consequences of the abnormalities in patients at a conscious level. This approach may help in turn to relate more easily the alterations observed experimentally and the phenomenological descriptions, inasmuch as both would concern subjective experience. Conversely, it may be useful to use micro-phenomenological approaches (Petitmengin \& Bitbol, 2009) to converge towards the moment-by-moment difficulties encountered in patients. Finally, an interesting approach could be to follow subjects with high risk of developing a schizophrenia spectrum disorder (ultra-high risk) longitudinally and to evaluate the possible primacy of the alterations of temporality on the disorders of the minimal self.

These approaches, once again, would not be used to equate phenomenology and elementary psychological mechanisms. Interpretations should remain cautious because of an irreducible gap between the personal experience and any approach aimed at uncovering its nature and mechanisms. But it may still help to improve our understanding of the impairments of the patients in each domain, in order to guide the development of therapeutics. It should be noted that new methods to bring phenomenological and experimental approaches together may apply to other pathologies with altered time consciousness, such as autism, which shows some genetic overlap with schizophrenia (Kushima et al., 2018). In this case also, there seems to be a difference in the experience of time, which is underlain by neurobiological mechanisms. Like in schizophrenia, the difficulty lies in relating these two levels. The remarks developed in the present manuscript are by no means restricted to schizophrenia only. The methods developed for one type of distorted time experience may apply to other distortions. 


\section{Conclusion}

The hypothesis of a strong link between alteration of the minimal self and temporality is attractive, and has received some support from the literature. However, this hypothesis remains difficult to document, even when crossing firstperson (especially phenomenological) and experimental psychology assessments.

We have briefly described some possible approaches to address the existing limits when trying to use both phenomenology and experimental psychology. We can conclude with Gallagher, who proposes a framework that allows for an original dialogue between the contribution and limits of phenomenology and cognitive science, with what he calls the front-load approach. Front-loading phenomenology postulates that:

Experiments can be informed by phenomenological insight. Such distinctions or insights, which are developed in independently conducted phenomenological analyses, can easily be incorporated into the design of behavioral ... experiments. In such cases,... phenomenology is "front-loaded" that is, incorporated into the design of the experiment, "up-front," in the experimental design. (Shaun Gallagher in Nowakowski et al., 2011, p. 79)

Such an approach can still be experimental, looking specifically at, for example, brain processes or objective measures of behavior. No phenomenological introspection has to be included in the experiment itself_-and this would make it different from a strictly neurophenomenological experiment. But the experiment may be viewed as confirming or raising questions informed by phenomenologyand such questions may be helpful for further phenomenological work (Gallagher \& Brøsted Sørensen, 2006). This approach is heuristic because both (phenomenological and experimental) domains can feed each other while admitting that they might address different types of phenomena. This approach is 
extremely useful in psychiatry, where the question of the relationship between elementary neurobiological and subjective impairments is a critical, unsolved question that prevents progress. In turn, the acknowledgement of this difficulty while using both experimental and phenomenological approaches might contribute to addressing this unsolved question.

Thus, following Gallagher's proposal, the building of experimental paradigms inspired by phenomenological insights (e.g., the Husserlian model) could be a promising way of designing a future research on timing and self disturbances in schizophrenia. This kind of approach would be in line with major issues of research on schizophrenia disorders aimed at better characterizing the fundamental outlines of schizophrenia and at developing therapeutic interventions targeting the basic mechanisms involved in the genesis of self disorders.

\section{Conflict of interest}

The authors have no conflicts of interest in this review. 


\section{References}

Binswanger, L. (1965). Wahn. Pfullingen, Germany: Neske. Blankenburg, W. (2001). First steps toward a 'psychopathology of common sense.' Philosophy, Psychiatry and Psychology, 8, 303-315. https://doi.org/10.1353/ppp.2002.0014 (Original work published 1969)

Buser, P., \& Debru, C. (2011). Le Temps, instant et durée: De la philosophie aux neurosciences. Paris, France: Odile Jacob.

Chapman, J. (1966). The early symptoms of schizophrenia. British Journal of Psychiatry: Journal of Mental Science, 112, 225-251. https://doi.org/10.1192/bjp.112.484.225

Ciullo, V., Spalletta, G., Caltagirone, C., Jorge, R. E., \& Piras, F. (2016). Explicit time deficit in schizophrenia: Systematic review and meta-analysis indicate it is primary and not domain specific. Schizophrenia Bulletin, 42, 505-518. https://doi.org/10.1093/schbul/sbv104

Coull, J., \& Nobre, A. (2008). Dissociating explicit timing from temporal expectation with fMRI. Current Opinion in Neurobiology, 18, 137-144. https://doi.org/10.1016/j.conb.2008.07.011

de Warren, N. (2009). Husserl and the promise of time. Cambridge: Cambridge University Press. https://doi.org/10.1017/ CBO9780511657412

Fuchs, T. (2007). The temporal structure of intentionality and its disturbance in schizophrenia. Psychopathology, 40, 229-235. https://doi.org/10.1159/000101365

Gallagher, S., \& Brøsted Sørensen, J. (2006). Experimenting with phenomenology. Consciousness and Cognition, 15, 119-134. https://doi.org/10.1016/j.concog.2005.03.002 
Gallagher, S., \& Zahavi, D. (2014). Primal impression and enactive perception. In V. Arstila \& D. Lloyd (Eds.), Subjective time (pp. 83-99). Cambridge, MA: MIT Press.

Giersch, A., Lalanne, L., \& Isope, P. (2016). Implicit timing as the missing link between neurobiological and self disorders in schizophrenia? Frontiers in Human Neuroscience, 10, 303. https://doi.org/10.3389/fnhum.2016.00303

Giersch, A., Lalanne, L., van Assche, M., \& Elliott, M. A. (2013). On disturbed time continuity in schizophrenia: An elementary impairment in visual perception? Frontiers in Psychology, 4, 281. https://doi.org/10.3389/fpsyg.2013.00281

Giersch, A., \& Mishara, A. (2017a). Disrupted continuity of subjective time in the milliseconds range in the self-disturbances of schizophrenia: Convergence of experimental, phenomenological, and predictive coding accounts. Journal of Consciousness Studies, 24, 62-87.

Giersch, A., \& Mishara, A. L. (2017b). Is schizophrenia a disorder of consciousness? Experimental and phenomenological support for anomalous unconscious processing. Frontiers in Psychology, 8, 1659. https://doi.org/10.3389/fpsyg.2017.01659

Giersch, A., Poncelet, P. E., Capa, R. L., Martin, B., Duval, C. Z., Curzietti, M., ... Lalanne, L. (2015). Disruption of information processing in schizophrenia: The time perspective.

Schizophrenia Research: Cognition, 2, 78-83. https://doi.org/10.1016/j.scog.2015.04.002

Haug, E., Oie, M., Melle, I., Andreassen, O. A., Raballo, A., Bratlien, U., ... Møller, P. (2012). The association between self-disorders and neurocognitive dysfunction in schizophrenia. Schizophrenia Research, 135, 79-83. https://doi.org/10.1016/j.schres.2011.11.015

Husserl, E. (2012). On the phenomenology of the consciousness of internal time (1893-1917) (J. B. Brough, Trans.). Berlin, Germany: Springer Science \& Business Media.

Jansson, L. B., \& Parnas, J. (2007). Competing definitions of schizophrenia: What can be learned from polydiagnostic studies? Schizophrenia Bulletin, 33, 1178-1200. https://doi.org/10.1093/schbul/sbl065 
Kushima, I., Aleksic, B., Nakatochi, M., Shimamura, T., Okada, T., Uno, Y., ... Ozaki N. (2018). Comparative analyses of copy-number variation in autism spectrum disorder and schizophrenia reveal etiological overlap and biological insights. Cell Reports, 24, 2838-2856. https://doi.org/10.1016/j.celrep.2018.08.022

Lalanne, L., van Assche, M., \& Giersch, A. (2012). When predictive mechanisms go wrong: Disordered visual synchrony thresholds in schizophrenia. Schizophrenia Bulletin, 38, 506-513. https://doi.org/10.1093/schbul/sbq107

Lalanne, L., van Assche, M., Wang, W., \& Giersch, A. (2012). Looking forward: An impaired ability in patients with schizophrenia? Neuropsychologia, 50, 2736-2744. https://doi.org/10.1016/j.neuropsychologia.2012.07.023

Mann, T. (1931). La montagne magique (M. Betz, Trans.). Paris, France: Artheme Fayard.

Martin, B., Franck, N., Cermolacce, M., Coull, J. T., \& Giersch, A. (2018). Minimal self and timing disorders in schizophrenia: A case report. Frontiers in Human Neuroscience, 12, 132. https://doi.org/10.3389/fnhum.2018.00132

Martin, B., Franck, N., Cermolacce, M., Falco, A., Benair, A., Etienne, E., ... Giersch, A. (2017). Fragile temporal prediction in patients with schizophrenia is related to minimal self disorders. Scientific Reports, 7, 8278. https://doi.org/10.1038/s41598-017-07987-y

Martin, B., Giersch, A., Huron, C., \& van Wassenhove, V. (2013). Temporal event structure and timing in schizophrenia: Preserved binding in a longer “now.”. Neuropsychologia, 51, 358-371. https://doi.org/10.1016/j.neuropsychologia.2012.07.002

Martin, B., Wittmann, M., Franck, N., Cermolacce, M., Berna, F., \& Giersch, A. (2014). Temporal structure of consciousness and minimal self in schizophrenia. Frontiers in Psychology, 5, 1175. https://doi.org/10.3389/fpsyg.2014.01175

Minkowski, E. (1933). Le temps vécu: Etudes phénoménologiques et psychopathologiques. Paris, France: Presses Universitaires de France. 
Mishara, A. L. (2010). Autoscopy: Disrupted self in neuropsychiatric disorders and anomalous conscious states. In S. Gallagher \& D. Schmicking (Eds.), Handbook of phenomenology and cognitive science (pp. 591-634). Dordrecht: Springer.

https://doi.org/10.1007/978-90-481-2646-0_30

Naudin, J. (1998). Phénoménologie et psychiatrie: Les voix et la chose. Toulouse, France: Presses Universitaires du Mirail.

Nelson, B., Parnas, J., \& Sass, L. A. (2014). Disturbance of minimal self (ipseity) in schizophrenia: Clarification and current status. Schizophrenia Bulletin, 40, 479-482. https://doi.org/10.1093/schbul/sbu034

Nelson, B., Thompson, A., \& Yung, A. R. (2012). Basic self-disturbance predicts psychosis onset in the ultra high risk for psychosis “prodromal” population. Schizophrenia Bulletin, 38, 1277-1287. https://doi.org/10.1093/schbul/sbs007

Nordgaard, J., Nilsson, L. S., Sæbye, D., \& Parnas, J. (2017). Self-disorders in schizophreniaspectrum disorders: A 5-year follow-up study. European Archives of Psychiatry and Clinical Neuroscience, 268, 713-718. https://doi.org/10.1007/s00406-017-0837-3

Nordgaard, J., Revsbech, R., Sæbye, D., \& Parnas, J. (2012). Assessing the diagnostic validity of a structured psychiatric interview in a first-admission hospital sample. World Psychiatry, 11, 181185. https://doi.org/10.1002/j.2051-5545.2012.tb00128.x

Northoff, G. (2017). The brain’s spontaneous activity and its psychopathological symptoms “Spatiotemporal binding and integration.”. Progress in Neuropsychopharmacology and Biological Psychiatry, 80(Pt B, 81-90. https://doi.org/10.1016/j.pnpbp.2017.03.019

Nowakowski, P., Podgórski, J. S., Pokropski, M., \& Wachowski, W. (2011). Interview with Shaun Gallagher-Part I: From Varela to a different phenomenology. AVANT, 2(2), 77-84. Retrieved from http://avant.edu.pl/wp-content/uploads/S-Gallagher-interview-I.pdf

Parnas, J. (2005). Clinical detection of schizophrenia-prone individuals: Critical appraisal. British 
Journal of Psychiatry, 48, s111-s112. https://doi.org/10.1192/bjp.187.48.s111

Parnas, J., \& Handest, P. (2003). Phenomenology of anomalous self-experience in early schizophrenia. Comprehensive Psychia try, 44, 121-134. https://doi.org/10.1053/comp.2003.50017

Parnas, J., Handest, P., Saebye, D., \& Jansson, L. (2003). Anomalies of subjective experience in schizophrenia and psychotic bipolar illness. Acta Psychiatrica Scandinavica, 108, 126-133. https://doi.org/10.1034/j.1600-0447.2003.00105.x

Parnas, J., \& Henriksen, M. G. (2014). Disordered self in the schizophrenia spectrum: A clinical and research perspective. Harvard Review of Psychiatry, 22, 251-265. https://doi.org/10.1097/HRP.0000000000000040

Parnas, J., Møller, P., Kircher, T., Thalbitzer, J., Jansson, L., Handest, P., \& Zahavi, D. (2005). EASE: Examination of Anomalous Self-Experience. Psychopathology, 38, 236-258. https://doi.org/10.1159/000088441

Petitmengin, C., \& Bitbol, P. (2009). The validity of first-person descriptions as authenticity and coherence. Journal of Consciousness Studies, 16, 363-404.

Poncelet, P. E., \& Giersch, A. (2015). Tracking visual events in time in the absence of time perception: Implicit processing at the ms level. PLoS One, 10, e0127106. https://doi.org/10.1371/journal.pone.0127106

Pöppel, E. (2009). Pre-semantically defined temporal windows for cognitive processing. Philosophical Transactions of the Royal Society of London. Series B, Biological Sciences, 364, 1887-1896. https://doi.org/10.1098/rstb.2009.0015

Posada, A., \& Franck, N. (2002). Use and automation of a rule in schizophrenia. Psychiatry Research, 109, 289-296. https://doi.org/10.1016/S0165-1781(02)00027-6

Raballo, A., \& Parnas, J. (2012). Examination of anomalous self-experience: Initial study of the structure of self-disorders in schizophrenia spectrum. Journal of Nervous and Mental Disease, 200, 577-583. https://doi.org/10.1097/NMD.0b013e31825bfb41 
Raballo, A., Sæbye, D., \& Parnas, J. (2011). Looking at the schizophrenia spectrum through the prism of self-disorders: An empirical study. Schizophrenia Bulletin, 37, 344-351. https://doi.org/10.1093/schbul/sbp056

Ricoeur, J. P. (1969). “Délire” de L. Binswanger et le recours à la phénoménologie transcendantale (compte-rendu, Questions de Méthode) (Unpublished doctoral dissertation). Marseille University, Marseille, France.

Sass, L. A. (2014). Self-disturbance and schizophrenia: Structure, specificity, pathogenesis (current issues, new directions). Schizophrenia $\quad$ Research, $152, \quad$ 15, https://doi.org/10.1016/j.schres.2013.05.017

Sass, L. A., \& Byrom, G. (2015). Self-disturbance and the bizarre: On incomprehensibility in schizophrenic delusions. Psychopathology, 48, 293-300. https://doi.org/10.1159/000437210

Sass, L. A., \& Parnas, J. (2003). Schizophrenia, consciousness, and the self. Schizophrenia Bulletin, 29, 427-444. https://doi.org/10.1093/oxfordjournals.schbul.a007017

Sass, L., Pienkos, E., Skodlar, B., Stanghellini, G., Fuchs, T., Parnas, J., \& Jones, N. (2017). EAWE: Examination of Anomalous World Experience. Psychopathology, 50, 10-54. https://doi.org/10.1159/000454928

Tatossian, A. (1979). La phénomenologie des psychoses. Puteaux, France: Le Cercle Herméneutique.

Thoenes, S., \& Oberfeld, D. (2017). Meta-analysis of time perception and temporal processing in schizophrenia: Differential effects on precision and accuracy. Clinical Psychology Review, 54, 4464. https://doi.org/10.1016/j.cpr.2017.03.007

Wiggins, O. P., Schwartz, M. A., \& Naudin, J. (2003). Rebuilding reality: A phenomenology of aspects of chronic schizophrenia. Seishin Shinkeigaky Zasshi. Psychiatria et Neurologia Japonica, 105, 1005-1015. 